\title{
Medical Toxicology and COVID-19: Our Role in a Pandemic
}

\author{
Natalie R. Neumann ${ }^{1} \cdot$ Peter R. Chai ${ }^{2,3,4,5} \cdot$ David M. Wood $^{6,7} \cdot$ Howard A. Greller $^{8} \cdot$ Mark B. Mycyk $^{9}$
}

Received: 13 April 2020 / Revised: 13 April 2020 / Accepted: 14 April 2020 / Published online: 30 April 2020

(C) American College of Medical Toxicology 2020

Keywords Pandemics $\cdot$ Poisoning $\cdot$ Toxicology $\cdot$ COVID-19 $\cdot$ Drug-related side effects and adverse reactions

Medical toxicology and infectious disease are not specialties traditionally associated with one another. Pandemics, however, have a way of disrupting convention, and in this era of modern medicine, our specialty has much to offer.

When a major medical crisis occurs for which there is no known cure, several phenomena may ensue. The public, fearful and increasingly connected to and influenced by social media, the internet, and television, may experiment with self-medication. Institutional bodies, desperate to advance care, may abandon the conventional mechanisms that ensure medication safety in order to facilitate the rapid approval and dissemination of novel pharmacotherapy. When these developments are considered within the context of our specialty, our role becomes clear. As medical toxicologists we serve as a fund of knowledge for our healthcare colleagues and the public: we provide physicians with information regarding antidotal therapy, drug-drug interactions, and novel therapeutics. We advise the public on an individual and community level through poison control centers and public outreach. As a specialty, we have the knowledge base and the position with respect to our peers and our society to monitor, prevent, and manage the toxicities born of a pandemic.

Accepting that medical toxicology has a role to play in an outbreak, we must also acknowledge that pandemics are not

Supervising Editor: Trevonne Thompson, MD

Natalie R. Neumann

natalie.neumann@cuanschutz.edu

1 Rocky Mountain Poison and Drug Center, Denver Health and Hospital Authority, Denver, CO 80204, USA

2 Division of Medical Toxicology, Department of Emergency Medicine, Brigham and Women's Hospital, Boston, MA, USA

3 Department of Psychosocial Oncology and Palliative Care, Dana Farber Cancer Institute, Boston, MA, USA

4 The Koch Institute for Integrated Cancer Research, Massachusetts Institute of Technology, Boston, MA, USA new; the COVID-19 epidemic is unlikely to be the last humankind will ever face. Therefore, the intent of this piece is to frame the role of our field in responding to pandemics not just today, but in the years to come.

The first and most obvious function of a medical toxicologist in a pandemic is to recognize and manage the acute and chronic toxicities associated with therapy. In the case of the SARS-CoV-2 coronavirus outbreak, extensive attention has been paid, appropriately, to chloroquine and hydroxychloroquine toxicity $[1,2]$. Poisoning from agents with antiviral activity is a high priority, and as such, $J M T$ features a well-timed review by Chary et al. on the adverse effects of nucleotide analogues, protease inhibitors, and monoclonal antibodies as prescribed for COVID-19 [3]. Given that our understanding of the epidemic evolves on a daily, even hourly basis, some of the information presented may require recurrent reassessment. Nevertheless, it serves as a helpful preliminary guide for clinicians. Treatment-associated toxicity, it should also be noted, encompasses not only medically sanctioned therapies, but also those interventions the general population unearths and applies from less reputable sources. Examples of potentially fatal home-brewed regimens used to treat coronavirus have included drinking bleach (sodium hypochlorite), insufflating cocaine, and consuming bootlegged alcohol adulterated with methanol [4-6]. Providing expertise with respect to the

5 The Fenway Institute, Boston, MA, USA

6 Clinical Toxicology, Guy's and St Thomas' NHS Foundation Trust and King's Health Partners, London, UK

7 Faculty of Life Sciences and Medicine, King's College London, London, UK

8 Division of Medical Toxicology, Department of Emergency Medicine, SBH Health Systems, New York City, NY, USA

9 Department of Emergency Medicine, Cook County Health, Chicago, IL 60612, USA 
treatment of toxicities born of the use and misuse of approved and alternative therapies is a service our field can readily provide to an otherwise overburdened medical system. Determining which of these poisoned patients may remain at home will not only reduce ED visits and hospital admissions but also limit microbial transmission.

Mastery in medical toxicology is predicated on an understanding of pharmacokinetics and pharmacodynamics. Here again, our specialty has a service to offer other medical fields. Anticipating and mitigating the adverse interactions which occur between those medications a patient takes routinely, and those he or she is prescribed to treat an infection, may spare hospital resources, physician confusion, and patient lives [7]. Hydroxychloroquine, for example, is a known cytochrome $\mathrm{p} 450$ inhibitor that has been demonstrated to increase the serum concentration of medications which may be fatal in overdose [8]. Remdesivir belongs to the nucleotide analog class of medications typically associated with mitochondrial inhibition. The idea of a mitochondrial poison being prescribed to thousands of patients within days could reasonably make a practitioner nervous. Concern is diminished, however, once one understands the range and timeframe of toxicity, and the fact that mitochondrial RNA polymerase inhibitors do not act synergistically with other mitochondrial toxins [9-11]. Understanding when and when not to be concerned about drug-drug interactions may help mitigate diagnostic uncertainty and prevent hazardous polypharmacy.

Relatedly, there is a role for toxicologists as a voice of caution with respect to novel therapeutic administration when information on toxicokinetics and drug safety is lacking. The non-randomized, non-blinded application of anti-malarial medications to thousands of severely ill patients with multiple comorbidities may be reasonably questioned. Similarly, the decision to administer on a large scale an antiviral agent that is undergoing FDA approval at an unprecedented pace is worthy of dialog [12]. By discussing with colleagues what level and kind of information is necessary to conclude that a drug is safe in any given patient population, we may reduce reflexive and potentially dangerous prescribing patterns. Participating in the design and implementation of clinical trials involving these agents may also provide opportunities to minimize risks to individuals under study and to obtain the safety data we need to protect the broader patient population.

Medical toxicologists are also capable of addressing the question of what infection itself does to drugs. The impact of medications on patient outcomes and viral infectivity is debated frequently and is yet another a discussion to which medical toxicology can contribute. A classic example is the ongoing debate surrounding ACE2 receptor density and the use of non-steroidal anti-inflammatory drugs and angiotensinconverting enzyme inhibitors in the setting of coronavirus infection [13-15]. Less commonly explored, however, is the impact a virus or bacteria may have on drug metabolism.
COVID-19, for example, is associated with hepatic derangements including transaminitis and microvesicular steatosis [16-19]. These findings have raised concerns that dosing regimens should be altered in the setting of infection [16]. But hepatic injury does not necessarily correlate to abnormal pharmacokinetics, and in this case, as with others, the mechanism of injury may not interfere at all with drug metabolism [20]. Interpreting the nature of end-organ dysfunction as it pertains to therapeutic drug administration and overdose is well within the wheelhouse of medical toxicology and represents both a service our field may provide and a potential research frontier.

It should also be recognized that by optimizing our standard practices we may improve outcomes and reduce strain on the healthcare system. Antidote stocking, a challenge at the best of times, may become more difficult as a pandemic escalates [21-23]. Ensuring adequate access to antidotal therapy, ideally prior to an epidemic's peak, may save lives and spare hospital resources. Recommendations for antidote stocking are available in an expert consensus document by Dart et al. from 2017 [24]. Similar guidance is available in the United Kingdom through the National Poisons Information Service and Royal College of Emergency Medicine [25]. Consideration may also be given to unconventional treatment regimens that allow appropriate patients to be treated at home and avoid hospital admission (e.g., oral fomepizole for toxic alcohol exposure, oral $\mathrm{N}$-acetylcysteine after acetaminophen ingestion, etc.). Lastly, poison centers, historically considered an underutilized source for reporting adverse drug reactions, may be more mindful of tracking and reporting toxicity from novel therapies [26]. Indeed, individual toxicologists can do the same and encourage their colleagues to use MedWatch, the FDA's medication safety reporting system, or the UK's MHPRA Yellow Card reporting system [27-29].

A final contribution our field can make is to monitor and potentially reduce the number of overdoses that might occur as a pandemic progresses. Colleagues in Europe have noted a precipitous drop in the number of ingestions reported since the institution of national and regional lockdowns. They are concerned that even though suicide rates may have decreased temporarily, if social isolation persists for months, citizens' mental health may deteriorate, leading to a rapid uptick in overdoses just as beds become scarce. Patients with substance use disorders, already at higher risk of suicide and overdose, may be disproportionately affected, especially if they are unable to access opioid agonist therapy during quarantine [30-32]. Transitioning to innovative models of continued care, be they telehealth visits or extended prescriptions for buprenorphine, may improve patient outcomes and reduce hospital strain. Identifying other at-risk populations and encouraging all providers to intervene early may save lives, generate constructive research, and inspire novel paradigms of care.

Surmounting a crisis requires the engagement of all parties. While medical toxicology may not be traditionally associated 
with viral pandemics, our field nevertheless has a part to play. Chary et al's up-to-date review is a must-read for front-line caregivers, policy makers, and even patients [3]. It reminds us of what is known and what is speculated, and it represents but one way in which we can help. Optimizing the treatment of poisoned patients, minimizing potentially dangerous polypharmacy, clarifying situations of diagnostic uncertainty, and limiting strains on hospital resources are all skills that we bring to the table. These acts may not inspire celebrity, but they are positive actions that can quietly improve outcomes in a highly pressurized, exceptional setting.

Funding Information Peter R Chai is funded by NIH K23DA044874; investigator-initiated research grants from Gilead Sciences, Philips Biosensing and e-ink corporation; and the Hans and Mavis Lopater Psychosocial Foundation.

\section{Compliance with Ethical Standards}

Conflict of Interest None.

\section{References}

1. Medical experts explain the use and potential adverse effects of chloroquine and hydroxychloroquine for COVID-19. 2020. https://www. acmt.net/Chloroquine_Webinar.html. Accessed 10 April 2020.

2. Vigdor N. Man fatally poisons himself while self-medicating for coronavirus, Doctor Says. The New York Times. 24 March 2020.

3. Chary MA, Barbuto AF, Izadmehr S, Hayes BD, Burns MM. COVID-19: therapeutics and their toxicities. J Med Toxicol. 2020;16(3). https://doi.org/10.1007/s13181-020-00777-5.

4. Myrick D. Blue Ridge Poison Center warning people not to drink bleach: CBS19 News. 2020. https://www.cbs19news.com/story/ 41893439/blue-ridge-poison-center-warning-people-not-to-drinkbleach. Accessed 10 April 2020.

5. Santé MdSedl. Non, La cocaïne NE protège PAS contre le \#COVID19 Twitter. 2020. https://twitter.com/MinSoliSante/status/ 1236626510703968257. Accessed 10 April 2020.

6. Corporation BB. Coronavirus: Iran reports leap in death toll BBC News. 2020. https://www.bbc.com/news/world-middle-east51801968.. Accessed 10 April 2020

7. Pirmohamed M, James S, Meakin S, Green C, Scott AK, Walley TJ, et al. Adverse drug reactions as cause of admission to hospital: prospective analysis of 18820 patients. Bmj. 2004;329(7456):15-9.

8. Somer M, Kallio J, Pesonen U, Pyykkö K, Huupponen R, Scheinin $\mathrm{M}$. Influence of hydroxychloroquine on the bioavailability of oral metoprolol. Br J Clin Pharmacol. 2000;49(6):549-54.

9. Lo MK, Jordan R, Arvey A, Sudhamsu J, Shrivastava-Ranjan P, Hotard AL, et al. GS-5734 and its parent nucleoside analog inhibit filo-, pneumo-, and paramyxoviruses. Sci Rep. 2017;7:43395.

10. Lewis W, Dalakas MC. Mitochondrial toxicity of antiviral drugs. Nat Med. 1995;1(5):417-22.

11. Tchesnokov EP, Feng JY, Porter DP, Götte M. Mechanism of inhibition of Ebola virus RNA-dependent RNA polymerase by remdesivir. Viruses. 2019;11(4):326.

12. Gilead. Gilead Sciences statement on request to rescind remdesivir orphan drug designation. 2020. https://www.gilead.com/news-andpress/company-statements/gilead-sciences-statement-on-request-torescind-remdesivir-orphan-drug-designation. Accessed 10 April 2020.
13. Fang L, Karakiulakis G, Roth M. Are patients with hypertension and diabetes mellitus at increased risk for COVID-19 infection? The Lancet Respiratory Medicine. 2020. https://oi.org/10.1016/ S2213-2600(20)30116-8.

14. Administration UFaD. FDA advises patients on use of nonsteroidal anti-inflammatory drugs (NSAIDs) for COVID-19. 2020. https:/www.fda.gov/drugs/drug-safety-and-availability/fdaadvises-patients-use-non-steroidal-anti-inflammatory-drugsnsaids-covid-19. Accessed 10 April 2020.

15. Kuba K, Imai Y, Rao S, Gao H, Guo F, Guan B, et al. A crucial role of angiotensin converting enzyme 2 (ACE2) in SARS coronavirusinduced lung injury. Nat Med. 2005;11(8):875-9.

16. Zhang C, Shi L, Wang F-S. Liver injury in COVID-19: management and challenges. Lancet Gastroenterol Hepatol. 2020;5:428-30.

17. Wang D, Hu B, Hu C, Zhu F, Liu X, Zhang J, et al. Clinical characteristics of 138 hospitalized patients with 2019 novel coronavirus-infected pneumonia in Wuhan, China. JAMA. 2020. https://doi.org/10.1001/jama.2020.1585.

18. Xu Z, Shi L, Wang Y, Zhang J, Huang L, Zhang C, et al. Pathological findings of COVID-19 associated with acute respiratory distress syndrome. Lancet Respir Med. 2020;8:420-2.

19. Chen N, Zhou M, Dong X, Qu J, Gong F, Han Y, et al. Epidemiological and clinical characteristics of 99 cases of 2019 novel coronavirus pneumonia in Wuhan, China: a descriptive study. Lancet. 2020;395(10223):507-13.

20. Bangash MN, Patel J, Parekh D. COVID-19 and the liver: little cause for concern. Lancet Gastroenterol Hepatol. 2020. https:// doi.org/10.1016/S2468-1253(20)30084-4.

21. Dart RC, Stark Y, Fulton B, Koziol-McLain J, Lowenstein SR. Insufficient stocking of poisoning antidotes in hospital pharmacies. JAMA. 1996;276(18):1508-10.

22. Juurlink DN, McGuigan MA, Paton TW, Redelmeier DA. Availability of antidotes at acute care hospitals in Ontario. CMAJ. 2001;165(1):27-30.

23. Thanacoody RH, Aldridge G, Laing W, Dargan PI, Nash S, Thompson JP, et al. National audit of antidote stocking in acute hospitals in the UK. Emerg Med J. 2013;30(5):393-6.

24. Dart RC, Borron SW, Caravati EM, Cobaugh DJ, Curry SC, Falk JL, et al. Expert consensus guidelines for stocking of antidotes in hospitals that provide emergency care. Ann Emerg Med. 2009;54(3):386-94.

25. Service NPI. Royal College of Emergency Medicine and National Poisons Information Service. Guideline on Antidote Availability for Emergency Departments. 2020. http://www.npis.org/ antidoteguideline.html. Accessed 10 April 2020.

26. Chyka PA, McCommon SW. Reporting of adverse drug reactions by poison control centres in the US. Drug Saf. 2000;23(1):87-93.

27. Administration UFaD. MedWatch: The FDA Safety Information and Adverse Event Reporting Program. 2020. https://www.fda. gov/safety/medwatch-fda-safety-information-and-adverse-eventreporting-program. Accessed 10 April 2020.

28. Gatti JC. The importance of physicians identifying and reporting adverse drug events. Am Fam Physician. 2012;85(4):318.

29. Agency MaHPR. Yellow Card. 2020. https://yellowcard.mhra.gov. uk. Accessed 10 April 2020.

30. Brent DA. Risk factors for adolescent suicide and suicidal behavior: mental and substance abuse disorders, family environmental factors, and life stress. Suicide Life Threat Behav. 1995;25:52-63.

31. Murphy GE. Suicide and substance abuse. Arch Gen Psychiatry. 1988;45(6):593-4.

32. Bohnert AS, Ilgen MA. Understanding links among opioid use, overdose, and suicide. N Engl J Med. 2019;380(1):71-9.

Publisher's Note Springer Nature remains neutral with regard to jurisdictional claims in published maps and institutional affiliations. 